\title{
Compare Forum: Challenging deficit discourses in international education and development
}

\author{
Introduction
}

\section{Sheila Aikman and Anna Robinson-Pant, University of East Anglia}

Research and policy in international education has often been framed in terms of a deficit discourse. For instance, policy debates on women's literacy and education have begun by positioning women as a group who need to 'catch up' on certain skills in order to become more active in development, or nomadic peoples are referred to as 'hard to reach' with formal education and in need of being educated into sedentary 'modern' ways of life. Rather than recognising the skills and knowledge that participants already have and practise in their everyday lives, researchers who adopt this deficit perspective on learning and education may find that the research agenda and questions will already be shaped to a large extent by the providers'/policy makers' standpoint. In applying these deficit terms, they may sometimes unintentionally reinforce research agendas embedded in dominant and mainstream policy which has led to discriminatory practice.

Within the international education and development research literature, a concern with the effects of adopting a deficit perspective on specific groups can be traced. Freire's (1970) critique of 'banking education' and the assumptions of learners as 'empty vessels' has posed the strongest challenge to pedagogical discourses based on this notion of deficit within classrooms and educational programmes. With regard to policy discourses, Escobar (1995: 109) investigated how development discourses influenced power relations in local and international contexts. His analysis of naming and 'the pervasive use of labels' (for instance through target groups and client categories) drew attention to the impact of such practices in reinforcing notions of deficit: 'Labels are by no means neutral: they embody concrete relationships of power and influence the categories with which we think and act'. Discussing language policy and research methodology, Cameron et al (1992) and Cameron (1994) distinguished between deficit, difference and diversity approaches and perspectives on language when researching on, for and with people. Building on this work and Robinson-Pant (2001), Rogers (2004) traced how three main paradigms - of deficit, of disadvantage and of difference - have influenced the planning for and implementation of educational and development programmes since the 1950s. The above body of work has drawn attention to the influence of deficit discourses on development policy and practice, as well as pedagogy and curriculum, and gone some way to propose alternative approaches.

In this Forum, we are interested to take the debate further by conceptualising 'deficit' in relation to two different areas of policy discourse dominant today. We examine discourses concerning specific groups of people who are often constructed in deficit terms, and we focus on policy discourses related to a specific thematic area within development which has been characterised by assumptions of deficit (Technical and Vocational Education and Training). This Forum takes the view that deficit discourses have shaped the questions and objectives of international educational research, influencing not only the way that researchers/policy makers look at specific groups in development and thematic policy areas, but also sometimes how people ('target groups') position and view themselves We set out to problematize these dominant deficit discourses in order to find alternative framings which allow different questions to be asked and to consider ways in which relationships around power, voice and identity can be reshaped. Our focus is on investigating the influence of discourses of deficit within policy, research and educational practice, where 'deficit' is constructed in terms of the lack of skills, attributes or resources. 
The Forum discussion papers have emerged from two BAICE-funded linked seminars organised at the University of East Anglia and University of Leeds by Anna Robinson-Pant, Caroline Dyer, Nitya Rao, Sheila Aikman, Alan Rogers and Spyros Themelis. We thank Caroline Dyer, Nitya Rao, Spyros Themelis and Alan Rogers for their contributions to these seminars and subsequent discussions. This Introduction discusses two framings of 'deficit' and sets the scene for the subsequent papers which build on presentations at the seminars by McGrath, Jere, Cheffy, and Rogers and Themelis. They investigate why and how dominant deficit discourses have influenced research agendas and explore alternative conceptual models.

The construction and (mis)representation of learners in policy and advocacy discourses

In the editorial of the 2012 Compare Special Issue $(42,2)$ : Developing Education, Challenging Marginalisation, Aikman and Dyer (2012) emphasised that education is a moral and political undertaking, and argued for the importance of understanding the underlying value frameworks that shape assumptions being made about education and the normative expectations bestowed on it. These include assumptions about: the ability of 'education' to change lives, broaden individuals' freedoms of choice and action, lifting people out of poverty, and the widely held belief that a lack of 'education' is a source of acute and persistent disadvantage. Viewed from this framing, particular groups of learners are constructed and (mis)represented in discourses of policy and advocacy, and their visibility is often achieved through deficit labelling: as 'the marginalised', 'indigenous', 'disabled', 'migrants', or a 'minority' with research agendas and policy being developed externally for them, rather than with and by 'them'. Such labelling defies the ways in which, for example, those people self-defining as 'indigenous' are diverse, multiple and engaged in advocacy and campaigning for justice, rights and educational self-determination (Aikman in BAICE 2015 p. 5). It also denies the initiatives that are successfully challenging dominant forms of education from primary schooling to higher education through affirmative action and new collaborations in part of countries such as Brazil and Mexico (McCowan BAICE 2015 p. 6).

High profile education policy advocacy publications have begun to equate 'education deprivation' with being 'vulnerable'. The World Bank's 2011 Learning for All document for example reinforces the equation of education with schooling, seen as 'the best tool for unleashing the potential of the human mind'. From this perspective, then, the so-called poor, vulnerable and disadvantaged populations who miss out on education or have low learning achievement scores are seen as valid targets for special treatment. The discourse of the High Level Panel (2013) reinforces a categorisation of groups with relatively low levels of schooling as 'vulnerable', including indigenous peoples, girls and women, ethnic minorities and Dalits, migrants, victims of gender-based violence, LGBTQI, small scale farmers, women, unemployed and the urban poor. The Sustainable Development Goal (SDG) 4 calls for equal access to all levels of education and vocational training for 'the vulnerable', a category which is explained to include persons with disability, indigenous peoples and 'girls in vulnerable situations'. What is not questioned is the quality and pertinence of the educational offer and how it is experienced by the people so categorised. Dyer (BAICE 2015 :72) notes in relation to pastoralists, for example, how there is little questioning of the relevance of what is to be reached and through what means, and that the ways in which mobility and labour organisation work together as a livelihood strategy is poorly understood in the education sector.

Ironically, deficit discourses themselves reflect a meta-narrative of 'inclusion': it is no coincidence that they are most in evidence when projects of universal education inclusion fail. The discourse of deficit draws attention to those who appear to have been left out; swiftly grouping them and then assuming one - or several - group characteristics. But no diagnosis of 'deficit' is neutral: they can be embedded in biases of culture, class, gender, age, race, ethnicity etc. which legitimise particular 
models of education and delegitimise others, producing en route 'failures' or 'difficult' groups. For example, the diverse and complex nature of disabilities means that many learners do not complete schooling, being forced out rather than dropping out (Shrestha, BAICE 2015 p.8). 'Deficit discourses' can also lead to over-representation of marginalised groups in 'alternative' education systems: and while such systems intend to address specific issues and provide flexible education, there is a danger of creating hierarchical systems of education which leaves 'mainstream' education as the most legitimate option and alternative education as an 'inclusive' option for those that most trouble its normative assumptions. When the primary deficit for pastoralists is assumed to be mobility, mobile schools are seen to be an answer; when the main deficit for indigenous groups' failure is seen to be language, intercultural bilingual schools are promoted as the solution.

While many labels have negative connotations there are contexts where they can also be seen as positive. Research on mother tongue education in Nepal demonstrates that some people embrace the term 'ethnic group' as part of their claims to a distinctive identity and as part of a self-making process used to demand justice and make claims on the state (Pradhan, BAICE 2015 p.10). Using those very labels of disadvantage can help to draw attention to the oversight by the state and turn the spotlight around. Furthermore, appropriating those labels re-signifies them as positive identities - demanding equality on the basis of the very grounds on which it had previously been denied. Reflections on language among indigenous peoples show, for example, that mother-tongue education can separate indigenous groups out from the mainstream in ways that are problematic and isolating; but conversely, it can raise awareness and bring local languages and identities into national education frameworks and transform the terms on which they are represented (see for example Cheffy, this Compare Forum).

Understanding who is utilising these labels and for what purposes is important and how they represent and (mis)represent others, but it is also important to question the extent to which they can be harnessed for new forms of self-representation and claims for educational rights, recognition and justice. As Jere (discusses in this Compare Forum, the label 'AIDS orphan' has replaced the traditional term 'anamasiye' (meaning 'children who have been left'), thereby ignoring the diverse and complex arrangements of parenting, fostering and family structures in Malawi. More attention needs to be given to how labels are received and used, how specific people thus identified in specific contexts engage with such characterisation.

Invisible or hidden? Challenging discourses around 'skills deficit'.

The second framing is concerned with challenging dominant policy discourses around skills development and training programmes in international education and development which start from an assumption of a deficit of skills and knowledge, both in the economy and with regard to individuals. As McGrath discusses in this Compare Forum, the orthodox vocational education and training account is redolent with language of deficit and moral culpability with millions of young people designated negative as not being in employment, education or training (NEET). These discourses are constructed from a perceived deficit of vocational education and training opportunities, rendering existing skills, literacy practices and skills development processes invisible and public providers castigated for their failure to make these young people into good citizenconsumers by addressing their employability. The NEET label, McGrath points out, is 'about what people are not, rather than what they are'.

Deficit discourses, largely constructing work as 'jobs', ignore questions of human flourishing and there is scant research that asks learners what they aspire to. Instead there is an assumption in 
many policy documents that vocational education itself is for 'deficit' groups - working class, blacks, who have been targets of such programmes aimed narrowly at ensuring they get a job and support economic development. This indicates the importance of breaking away from labelling of institutions and learners as 'failures' and the long colonial legacy of vocational education around the world, in order to recognise that technical solutions to vocational education will not address the complex social problems that exist.

Literacy training figures strongly in the discourses on vocational education. Rogers (BAICE 2015, p.13 and in this Compare Forum) argues that the deficit discourse is caused by a narrow definition of skills, training and literacy in policy. By advising people to learn literacy before seeking vocational training opportunities their informal literacy practices and skills are overlooked and denied. Again, this points to the importance of understanding participants' and learners' aspirations and values. This approach is confined not only to vocational educational contexts, but can also be found in academic institutions. Students - particularly those coming from non-traditional higher education groups and from other cultural and linguistic contexts - bring diverse academic literacy practices and learning styles which can serve as resources. However, often such practices may not be valued or recognised within higher educational classrooms, particularly with the pressures for universally comparable measures of outcomes within assessment regimes.

Finding alternative discourses and spaces

Within this Compare Forum, the authors reflect not only on the limitations of either 'reproducing or resisting the way of the state', but also consider what alternatives there could be. By contrast with the other contributors, Cheffy explores how far a deficit perspective can actually 'be a strong motivator for growth and development' on the part of providers and communities. Formal education invariably has 'winners and losers' built into the system so within this context inequalities and deficit discourses become inevitable. Several of these articles focus primarily on policy discourses, illustrating the ways in which deficit discourses can prevent policy makers and practitioners on the ground (including teachers) from seeing beyond the label and recognising, as Shrestha (BAICE 2015) points out, the 'uniqueness of learners'. However, perhaps policy is not the answer: rather than challenging policy categories such as 'NEET' or 'AIDS orphans', we can also set out to find alternative spaces to facilitate social change.

The growing importance of social media and rapid spread of ICT needs to be considered not only in terms of the 'skills' that are required for economic growth, but also as alternative modes of learning and communication. Such new technologies are leading to alternative and innovative ways of using language and new modalities of learning and communicating, which offer young people in particular the opportunity to develop new identities and voice their views in public spaces. This kind of positioning is in stark contrast to the policy contexts described by Rogers and Themelis where people 'are invited to occupy the category that has been constructed for them'. However, as the same article suggests in relation to the 'misrepresentation' of certain groups in TV programmes, the new and old media should be treated with caution. Education has an important role to play within such processes. This is partly about providing the skills to engage with new digital technologies, but also about facilitating a more critical understanding of how knowledge is constructed and communicated.

The contributors to this Compare Forum share a dissatisfaction with the ways in which policy discourses around deficit have led to the neglect of or misrepresentation of certain groups whether young unemployed women in the UK or pastoralists in Ethiopia. We hope that this collection of reflective pieces will highlight the effects of viewing people and thematic areas (such as 
TVET) through a deficit lens. More importantly, this Compare Forum aims to raise new questions and point to new directions beyond the bounds of education and development policy.

References:

Aikman, S. and Dyer, C. (2012) Education and Inclusion: Re-examining the Narratives. Compare Vol. 42, No.2, pp. 177-185.

BAICE 2015 Challenging deficit discourses in international education and development (BAICE Thematic Forum Report) https://www.uea.ac.uk/education/research/areas/literacy-anddevelopment/conferences-and-seminars.

Cameron, D. (1994) Verbal Hygiene Applied Linguistics Vol.15, No.4,pp. 382-398

Cameron, D., Frazer, E., Harvey, P., Rampton, B. and K. Richardson (1992) Researching Language: issues of power and method, Routledge, London.

Escobar, A. (1995) Encountering Development: the making and unmaking of the Third World, Princeton University Press, New Jersey

Freire, P. (1970) Pedagogy of the Oppressed, Continuum Press

Robinson-Pant, A. (2001) Development as Discourse: what relevance to education? Compare, Vol. 31, No. 3, 311- 328

Rogers, A. (2004) Non-formal Education: flexible schooling or participatory education? Hong Kong University Press 